\title{
Comparative Study of Radiation Shielding Parameters for Bismuth Borate Glasses
}

\author{
Rajinder Singh Kaundal * \\ ${ }^{a}$ Department of Physics, School of Physical Sciences, Lovely Professional University, Phagwara, \\ Punjab, 144411, India
}

Received: January 20, 2016; Revised: April 5, 2016; Accepted: May 6, 2016

\begin{abstract}
Melt and quench technique was used for the preparation of glassy samples of the composition $\mathrm{x} \mathrm{Bi}_{2} \mathrm{O}_{3}-(1-\mathrm{x}) \mathrm{B}_{2} \mathrm{O}_{3}$ where $\mathrm{x}=.05$ to .040 . XCOM computer program is used for the evaluation of gamma-ray shielding parameters of the prepared glass samples. Further the values of mass attenuation coefficients, effective atomic number and half value layer for the glassy samples have been calculated in the energy range from $1 \mathrm{KeV}$ to $100 \mathrm{GeV}$. Rigidity of the glass samples have been analyzed by molar volume of the prepared glass samples.
\end{abstract}

Keywords: Glasses, Molar Volume, Density, Mass attenuation coefficient, Half value layer, Effective atomic number

\section{Introduction}

The study of interaction of nuclear radiations with matter is the important research area for the development of materials which can be used in high radiation environment $t^{1-3}$. These radiation shielding materials have great importance for many scientific, engineering and medical applications. The data based on mass attenuation coefficient and half value layer is very useful for the purpose to identify the various radiation shielding materials. In the environment of high radiation exposure concrete is used as radiation shielding material because it is cheap and it can be molded easily into any desired design.

In spite of all these advantages some limitation are also associated with the concretes like it is not transparent to visible light thus restricting one to see through it. Secondly when it is exposed to the radiations for a longer period of time its mechanical strength is reduced. So it is desired to have materials which are transparent to visible light and have better shielding properties in terms of lesser volume requirement. Now a day heavy metal glasses are proving to be the promising candidates as an alternate to the conventional shielding material like concrete ${ }^{4-11}$. The commonly used heavy metal in glasses is lead. But due to its toxic nature its use in heavy metal glasses is discouraged. Borate and Silicate are the most commonly used glass formers because of their easy availability and low cost. Boron belongs to the group III of periodic table and the elements of this group find wide range of applications including their scope in the field of solar cells ${ }^{12-15}$. In the present paper bismuth based systems are undertaken because they are non toxic to our environment and can be new possibility for a lead free radiation shielding glass. Also these bismuth bases glasses have considerable technological applications due to their density, high refractive index and low melting point ${ }^{16}$. Sol-Gel and

* e-mail: rajinder_apd@yahoo.com melt quench techniques are used to prepare glasses, in the present article the author has employed melt-quench technique to prepare glass sample ${ }^{17}$.

\subsection{Novelty of work}

The bismuth borate glasses are non toxic to environment and can provide alternate to lead free shielding materials. Also these have advantage to conventional shielding materials in terms of their better shielding properties. These glasses ate transparent to visible light and have low melting points. Further high density values and high refractive index of these glasses make them of great importance for many technical applications. Author have prepared these glass systems by using melt and quench technique and their properties are studied in terms of mass attenuation coefficient and density measurements. Results indicate that these glasses can be alternate for concretes which are opaque and require much larger volume measured in terms of half value layer.

\section{Materials and computational method}

\subsection{Sample preparation, X-ray and density measurements}

Glass samples of the chemical compositions given in table1 have been prepared by using the melt quenching technique All the chemicals used in the sample preparation were of analytical reagent (AR) grade having percentage purity of $99.9 \%$. Appropriate amounts of $\mathrm{Bi}_{2} \mathrm{O}_{3}$ and $\mathrm{H}_{3} \mathrm{BO}_{3}$ were mixed thoroughly. Mixture was then taken in porcelain crucible and was melted to a temperature of $1200^{\circ} \mathrm{C}$ and the melt was kept at the same temperature for 2 hours. Melt was quickly poured into preheated moulds in the temperature region of 200 to $250^{\circ} \mathrm{C}$ followed by cooling down to room temperature.

Densities of the samples at room temperature were measured by using Archmede's principle with Benzene 
as immersion liquid. Glass samples were weighed in air and when immersed in Benzene at $20^{\circ} \mathrm{C}$. The density was calculated by using the formula

$$
\rho=a /(a-b) \times 0.8756
$$

Where $\rho$ is the density of glass sample, a is weight of sample in air, b is weight of glass sample in Benzene and 0.8756 is the density of Benzene at $20^{\circ} \mathrm{C}$. The values of density along with composition and $\mathrm{R}$ value $(\mathrm{R}=$ Mole fraction of $\mathrm{Bi}_{2} \mathrm{O}_{3} /$ Mole fraction of $\mathrm{B}_{2} \mathrm{O}_{3}$ ) are given in table 1 .

Table 1: Chemical compositions and $\mathrm{R}$ value (Bismuth to Borate ratio)

\begin{tabular}{lccc}
\hline Sample Name & $\mathrm{Bi}_{2} \mathrm{O}_{3}$ & $\mathrm{~B}_{2} \mathrm{O}_{3}$ & $\mathrm{R}\left(\mathrm{Bi}_{2} \mathrm{O}_{3} / \mathrm{B}_{2} \mathrm{O}_{3}\right)$ \\
\hline GS1 & 0.05 & 0.95 & 0.052 \\
GS2 & 0.10 & 0.90 & 0.11 \\
GS3 & 0.15 & 0.85 & 0.17 \\
GS4 & 0.20 & 0.80 & 0.25 \\
GS5 & 0.25 & 0.75 & 0.33 \\
GS6 & 0.30 & 0.70 & 0.42 \\
GS7 & 0.35 & 0.65 & 0.53 \\
GS8 & 0.40 & 0.60 & 0.66 \\
\hline
\end{tabular}

To confirm the amorphous nature glass samples XRD measurements were carried out on the prepared samples. Samples were crushed to fine powder form for X-ray diffraction studies. A Philips PW 1710 diffractrometer was used during the investigations. Radiation used was $\mathrm{CuK} \alpha$. The pattern was recorded at a scanning rate $(2 \theta / \mathrm{s})$ of 0.030 with start angle $(2 \theta)$ at $5.010^{\circ}$ and end angle $(2 \theta)$ at $60.0^{\circ}$ Absence of crystallization peak in XRD data shows that prepared samples are amorphous.

\subsection{Linear attenuation coefficients and effective atomic number}

The mass attenuation coefficient of prepared samples is evaluated by using WIN XCOM ${ }^{3,4}$ developed by NIST. HVL have been determined by mass attenuaton coefficient by using the relation

$$
\text { HVL }=0.693 / \mu
$$

Effective atomic number can be calculated by using relation

$$
\mathrm{Z}_{\mathrm{eff}}=\sigma_{\mathrm{t}, \mathrm{a}} / \sigma_{\mathrm{t}, \mathrm{el}}
$$

Where the average atomic cross-section, $\sigma_{t, a}$ is evaluated by using equation

$$
\sigma_{\mathrm{t}, \mathrm{a}}=\sigma_{\mathrm{t}, \mathrm{m}} / \sum_{i} n_{i}
$$

$\sigma_{\mathrm{t}, \mathrm{m}}$ is the total molecular interaction cross-section $\sigma_{t, m}=(\mu / \rho) M / N_{A}$, where $M=\sum n_{i} A_{i}$ is the molar mass, $\mathrm{N}_{\mathrm{A}}$ is Avogadro's constant and $\mathrm{n}_{\mathrm{i}}$ and $\mathrm{A}_{\mathrm{i}}$ are the number of formula units and atomic weight, respectively of constituent elements.

Average electronic cross-section, $\mathrm{s}_{\mathrm{t}, \mathrm{el}}$ is given by

$$
\sigma_{\mathrm{t}, \mathrm{el}}=1 / \mathrm{N}_{\mathrm{A}} \sum \mathrm{f}_{i} \mathrm{~A}_{i} / \mathrm{Z}_{i}(\mu / \rho)
$$

where $f_{i}=n_{i} / \sum n_{j}$ is fractional abundance of element $i$ with respect to number of atoms and $Z_{i}$ is atomic number of $i$ element.

\section{Results and Discussions}

\subsection{Density and molar volume}

Density and molar volume values of the prepared samples are shown in figure1. The values of density increase from GS1 to GS8 with increase in R value (bismuth to borate ratio) showing the effect of addition of bismuth at the expense of borate. The molar volume also show linear increase depicting that structure becomes more and more open as light metal atom is changed with heavier one ${ }^{18}$. The value of molar volume is maximum for the composition corresponding to $\mathrm{R}=0.66$. It can be due to the fact that $\mathrm{Bi}$ ions play dual role in the glass structure. At higher mole fraction the role of $\mathrm{Bi}$ ions in the glass structure is of glass former.

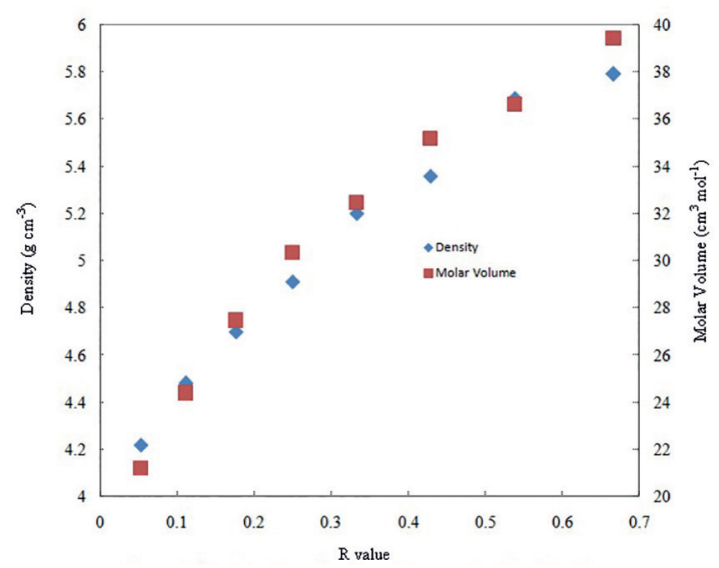

Figure 1: Plot of density and molar volume as a function of R value.

\subsection{Linear attenuation coefficients}

The values of mass attenuation coefficients for the various samples are shown in table 2 from energy range $1 \mathrm{KeV}$ to $100 \mathrm{GeV}$. It can be observed that the mass attenuation coefficient values are very high in low energy range for which photoelectric effect is dominant. The values of mass attenuation coefficients as evident from table 2 shows rapid decrease attaining minimum value in the intermediate energy range. As one moves from intermediate energy range corresponding to Compton scattering region to high energy range corresponding to pair production the values of mass attenuation coefficient 
Table 2: Mass attenuation coefficients for prepared glass samples at different energies.

\begin{tabular}{lccccccccc}
\hline \multirow{2}{*}{ Sample } & \multicolumn{7}{c}{ Mass Attenuation coefficient $\mu / \rho\left(\mathrm{cm}^{2} / \mathrm{g}\right)$} \\
& $0.001 \mathrm{MeV}$ & $0.01 \mathrm{MeV}$ & $0.1 \mathrm{MeV}$ & $1 \mathrm{MeV}$ & $10 \mathrm{MeV}$ & $100 \mathrm{MeV}$ & $1000 \mathrm{MeV}$ & $10000 \mathrm{MeV}$ & $100000 \mathrm{MeV}$ \\
\hline GS1 & $5.12 \mathrm{E}+03$ & $1.07 \mathrm{E}+02$ & $4.51 \mathrm{E}+00$ & $7.01 \mathrm{E}-02$ & $4.37 \mathrm{E}-02$ & $7.72 \mathrm{E}-02$ & $9.49 \mathrm{E}-02$ & $9.86 \mathrm{E}-02$ & $9.92 \mathrm{E}-02$ \\
$\mathrm{GS} 2$ & $4.32 \mathrm{E}+03$ & $5.49 \mathrm{E}+01$ & $2.29 \mathrm{E}+00$ & $6.61 \mathrm{E}-02$ & $3.15 \mathrm{E}-02$ & $4.61 \mathrm{E}-02$ & $5.62 \mathrm{E}-02$ & $5.84 \mathrm{E}-02$ & $5.88 \mathrm{E}-02$ \\
GS3 & $4.53 \mathrm{E}+03$ & $6.85 \mathrm{E}+01$ & $2.86 \mathrm{E}+00$ & $6.71 \mathrm{E}-02$ & $3.47 \mathrm{E}-02$ & $5.41 \mathrm{E}-02$ & $6.62 \mathrm{E}-02$ & $6.89 \mathrm{E}-02$ & $6.93 \mathrm{E}-02$ \\
GS4 & $4.68 \mathrm{E}+03$ & $7.84 \mathrm{E}+01$ & $3.29 \mathrm{E}+00$ & $6.79 \mathrm{E}-02$ & $3.70 \mathrm{E}-02$ & $6.01 \mathrm{E}-02$ & $7.36 \mathrm{E}-02$ & $7.65 \mathrm{E}-02$ & $7.70 \mathrm{E}-02$ \\
GS5 & $4.79 \mathrm{E}+03$ & $8.61 \mathrm{E}+01$ & $3.61 \mathrm{E}+00$ & $6.85 \mathrm{E}-02$ & $3.88 \mathrm{E}-02$ & $6.46 \mathrm{E}-02$ & $7.92 \mathrm{E}-02$ & $8.24 \mathrm{E}-02$ & $8.28 \mathrm{E}-02$ \\
GS6 & $4.89 \mathrm{E}+03$ & $9.21 \mathrm{E}+01$ & $3.87 \mathrm{E}+00$ & $6.89 \mathrm{E}-02$ & $4.02 \mathrm{E}-02$ & $6.82 \mathrm{E}-02$ & $8.37 \mathrm{E}-02$ & $8.70 \mathrm{E}-02$ & $8.75 \mathrm{E}-02$ \\
GS7 & $4.96 \mathrm{E}+03$ & $9.70 \mathrm{E}+01$ & $4.07 \mathrm{E}+00$ & $6.93 \mathrm{E}-02$ & $4.13 \mathrm{E}-02$ & $7.11 \mathrm{E}-02$ & $8.73 \mathrm{E}-02$ & $9.07 \mathrm{E}-02$ & $9.12 \mathrm{E}-02$ \\
GS8 & $5.02 \mathrm{E}+03$ & $1.01 \mathrm{E}+02$ & $4.25 \mathrm{E}+00$ & $6.96 \mathrm{E}-02$ & $4.22 \mathrm{E}-02$ & $7.35 \mathrm{E}-02$ & $9.03 \mathrm{E}-02$ & $9.38 \mathrm{E}-02$ & $9.43 \mathrm{E}-02$ \\
\hline
\end{tabular}

first show increase and at very high values of the energy the values become almost constant ${ }^{19}$.

\subsection{Effective atomic numbers and half value layer}

The scattering and absorption of gamma radiations are related to the effective atomic number of the materials ${ }^{20}$. These values are calculated using equation 3 and variation for the prepared samples is shown in figure 2. It can be seen from the figure that for all the samples the $Z_{\text {eff }}$ steadily increases up to $10^{-2} \mathrm{MeV}$, then it steadily decreases up to $10^{\circ} \mathrm{MeV}$ after which it increases up to $10^{2} \mathrm{MeV}$ after this energy the values of $Z_{\text {eff }}$ almost remains constant. The variation of $Z_{\text {eff }}$, value with energy for the samples materials may can be assigned due to the relative domination of different mechanisms mainly photoelectric effect, coherent scattering and incoherent scattering. At low energies, where photoelectric effect dominates, $Z_{\text {eff }}$ is more and at higher energies, where scattering dominates, $Z_{\text {eff }}$ is less. Therefore, the $Z_{\text {eff }}$ for total gamma ray interaction varies from a higher value at lower energies to a lower value at higher energies depending on the relative domination of the partial gamma ray interaction processes. Effective atomic

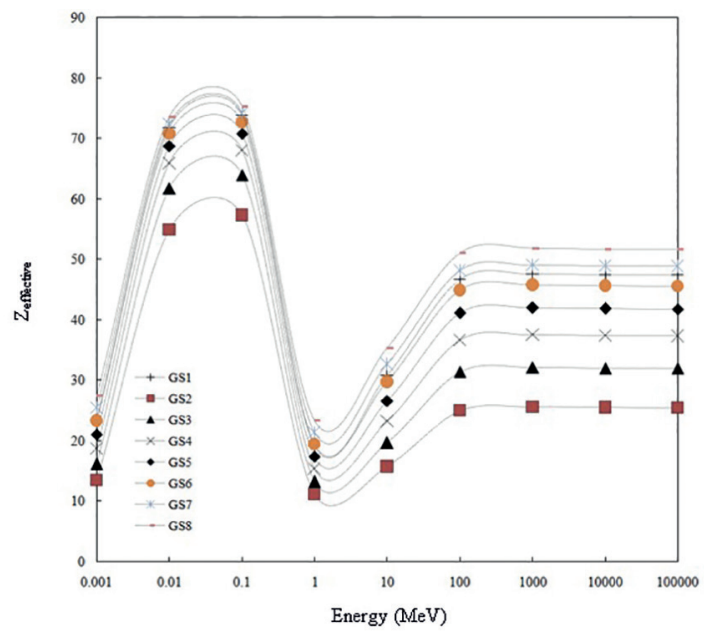

Figure 2: Plot of Effective atomic number for the prepared glass samples as a function of photon energy. numbers increases linearly as we increase the bismuth to borate ratio. Value of effective number is maximum for the sample GS8 correspondind to $\mathrm{R}=0.66$. Higher values of effective number corresponds to more effective shielding from gamma radiations. Higher value of mass attenuation coefficient corresponding to GS8 suggests that this sample can shield the gamma radiations more effectively.

Half value layer parameter is calculated from the linear attenuation coefficient using equation 2. Values of HVL are given in table 3. It can be seen that HVL decreases with $R$ value suggesting that with increase in $\mathrm{R}$ value the shielding properties are improved.

HVL is not only composition dependent but it also dependent upon the density of material which is further related to the structural arrangements of constituents of composite material. This parameter is very important for the materials to be used as the radiation shield. For this purpose, HVL values of the prepared glasses have been compared with some standard radiation shielding concretes (Table 4).

For this glass sample GS8 is taken for the comparison purpose since its HVL value is minimum among all the prepared glass samples. Figure 3 shows comparative plot of the HVL value for various concretes and GS8 sample. It can be clearly seen that for the prepared sample (GS8), value of HVL at all the energies is lesser than the concretes.

\section{Conclusions}

In the present paper gamma ray shielding properties of bismuth borate glasses have been investigated and compared with concretes. GS8 is found to have lowest HVL values in all the prepared samples. Further the mass attenuation for the sample GS8 is highest out of all the prepared samples. The concretes on the other hand have more value for HVL. These findings suggest that the $\mathrm{Bi}$ containing glasses can be used as alternate to the concretes as radiation shielding materials. Further these are transparent to visible light and require lesser volume estimated in terms of HVL as compared to concretes which are opaque and require much larger volume. The present investigation results are also significant as Bismuth is non toxic to environment and can provide suitable lead free shielding materials. 
Table 3: HVL values for prepared glass samples at different energies.

\begin{tabular}{lccccccccc}
\hline \multirow{2}{*}{ Sample } & \multicolumn{7}{c}{ HVL(cm) } \\
& $0.001 \mathrm{MeV}$ & $0.01 \mathrm{MeV}$ & $0.1 \mathrm{MeV}$ & $1 \mathrm{MeV}$ & $10 \mathrm{MeV}$ & $100 \mathrm{MeV}$ & $1000 \mathrm{MeV}$ & $10000 \mathrm{MeV}$ & $100000 \mathrm{MeV}$ \\
\hline GS1 & $3.20894 \mathrm{E}-05$ & 0.001532327 & 0.036414 & 2.343301 & 3.761516 & 2.127239 & 1.731114 & 1.665977716 & 1.656402166 \\
GS2 & $3.58425 \mathrm{E}-05$ & 0.002819977 & 0.067628 & 2.341588 & 4.907458 & 3.36009 & 2.754711 & 2.647709494 & 2.631946638 \\
GS3 & $3.25943 \mathrm{E}-05$ & 0.002154702 & 0.051498 & 2.197398 & 4.252865 & 2.724222 & 2.227599 & 2.142183903 & 2.129502768 \\
GS4 & $3.01798 \mathrm{E}-05$ & 0.001800322 & 0.042938 & 2.079559 & 3.816741 & 2.350279 & 1.918745 & 1.845506702 & 1.834714265 \\
GS5 & $2.78072 \mathrm{E}-05$ & 0.001549189 & 0.036917 & 1.94695 & 3.439311 & 2.063267 & 1.682753 & 1.618794078 & 1.609413163 \\
GS6 & $2.64638 \mathrm{E}-05$ & 0.001404674 & 0.033444 & 1.876227 & 3.22113 & 1.896588 & 1.545696 & 1.487045627 & 1.478545309 \\
GS7 & $2.45571 \mathrm{E}-05$ & 0.001256604 & 0.029904 & 1.757723 & 2.951254 & 1.713712 & 1.395987 & 1.34304672 & 1.335391516 \\
GS8 & $2.38351 \mathrm{E}-05$ & 0.001185383 & 0.028203 & 1.719673 & 2.83571 & 1.629115 & 1.326578 & 1.276371658 & 1.269065735 \\
\hline
\end{tabular}

Table 4: Chemical composition of concretes.

\begin{tabular}{|c|c|c|c|c|c|c|c|c|c|c|c|c|c|c|c|}
\hline \multirow{2}{*}{ Concretes } & \multicolumn{14}{|c|}{ Wt. Fraction } & \multirow{2}{*}{ Density } \\
\hline & $\mathrm{H}$ & B & $\mathrm{C}$ & $\mathrm{O}$ & $\mathrm{Na}$ & $\mathrm{Mg}$ & $\mathrm{Al}$ & $\mathrm{Si}$ & S & K & $\mathrm{Ca}$ & $\mathrm{Cr}$ & $\mathrm{Fe}$ & $\mathrm{Ba}$ & \\
\hline Ordinary & 0.1000 &.. & 0.0010 & 0.5291 & 0.0160 & 0.0020 & 0.0338 & 0.3370 & .. & 0.0130 & 0.0440 & .. & 0.0140 & $\ldots$ & 2.3 \\
\hline Barite & 0.0083 & 0.0115 &.. & 0.3475 &.. & 0.0022 & 0.0044 & 0.0148 & 0.0997 &.. & 0.0834 & $\ldots$ & 0.0047 & 0.4237 & 3.5 \\
\hline Ferrite & 0.0280 &.. & $\ldots$ & 0.4554 & .. & 0.0019 & 0.0038 & 0.0128 & 0.0007 &.. & 0.0595 & $\ldots$ & 0.4378 &.. & 4.5 \\
\hline Chromite & $\ldots$ & .. & 0.0006 & 0.3670 & 0.0088 & 0.0593 & 0.0535 & 0.0443 & 0.0061 & .. & 0.0364 & 0.3423 & 0.0804 & .. & 3.27 \\
\hline Serpentite & 0.0128 & 0.0061 &.. & 0.5136 & $\ldots$ & 0.1705 & 0.0215 & 0.1587 & 0.0046 &.. & 0.0677 & $\ldots$ & 0.0441 &.. & 1.95 \\
\hline
\end{tabular}

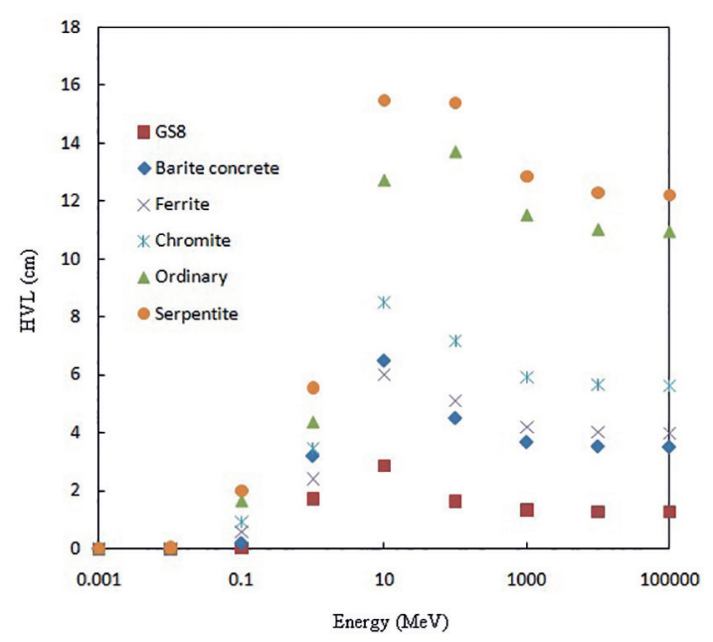

Figure 3: Plot of HVL $(\mathrm{cm})$ for various concretes and GS8 as a function of photon energy.

\section{References}

1. Kaur U, Sharma JK, Singh PS, Singh T. Comparative studies of different concretes on the basis of some photon interaction parameters. Applied Radiation and Isotopes. 2012;70(1):233-240.

2. Singh C, Singh T, Kumar A, Mudahar GS. Energy and chemical composition dependence of mass attenuation coefficients of building materials. Annals of Nuclear Energy. 2004;31(10):1199-1205.

3. Bashter I. Calculation of radiation attenuation coefficients for shielding concretes. Annals of Nuclear Energy. 1997;24(17):1389-1401.

4. Singh N, Singh KJ, Singh K, Singh H. Gamma-ray attenuation studies of $\mathrm{PbO}-\mathrm{BaO}-\mathrm{B}_{2} \mathrm{O}_{3}$ glass system. Radiation Measurements. 2006;41(1):84-88
5. Kaewkhao J, Limsuwan P. Mass attenuation coefficients and effective atomic numbers in phosphate glass containing $\mathrm{Bi}_{2} \mathrm{O}_{3}$, $\mathrm{PbO}$ and $\mathrm{BaO}$ at $662 \mathrm{keV}$. Nuclear Instruments and Methods in Physics Research Section A: Accelerators, Spectrometers, Detectors and Associated Equipment. 2010;619(1-3):295-297.

6. Kurudirek M, Özdemir Y, Şimşek Ö, Durak R. Comparison of some lead and non-lead based glass systems, standard shielding concretes and commercial window glasses in terms of shielding parameters in the energy region of $1 \mathrm{keV}-100 \mathrm{GeV}$ : A comparative study. Journal of Nuclear Materials. 2010;407(2):110-115.

7. Kirdsiri K, Kaewkhao J, Chanthima N, Limsuwan P. Comparative study of silicate glasses containing $\mathrm{Bi}_{2} \mathrm{O}_{3}, \mathrm{PbO}$ and $\mathrm{BaO}$ : Radiation shielding and optical properties. Annals of Nuclear Energy. 2011;38(6):1438-1441.

8. Singh K, Singh H, Sharma V, Nathuram R, Khanna A, Kumar $\mathrm{R}$, et al. Gamma-ray attenuation coefficient in bismuth borate glass. Nuclear Instruments and Methods in Physics Research Section B: Beam Interactions with Materials and Atoms. 2002;194(1):1-6.

9. Singh K, Singh H, Sharma G, Gerward L, Khanna A, Kumar R, et al. Gamma-ray shielding properties of $\mathrm{CaO}-\mathrm{SrO}-\mathrm{B}_{2} \mathrm{O}_{3}$ glasses. Radiation Physics and Chemistry. 2005;72(2-3):225-228.

10. Singh S, Kumar A, Singh D, Thind KS, Mudahar GS. Bariumborate-flyash glasses: As radiation shielding materials. Nuclear Instruments and Methods in Physics Research Section B: Beam Interactions with Materials and Atoms. 2008;266(1):140-146.

11. Limkitjaroenporn P, Kaewkhao J, Limsuwan P, Chewpraditkul W. Physical, optical, structural and gamma-ray shielding properties of lead sodium borate glasses. Journal of Physics and Chemistry of Solids. 2011;72(4):245-251.

12. Pathak D, Wagner T, Adhikari T, Nunzi JM. Photovoltaic performance of AgInSe2-conjugated polymer hybrid system bulk heterojunction solar cells. Synthetic Materials. 2015;199:87-92.

13. Pathak D, Wagner T, Adhikari T, Nunzi JM. AgInSe2.PCBM. P3HT inorganic organic blends for hybrid bulk heterojunction photovoltaics. Synthetic Materials. 2015;200:102-108. 
14. Pathak D, Bedi RK, Kaur D. Effect of Substrate Temperature on the Structural, Optical, and Electrical Properties of Silverindium-selenide Films Prepared by Using Laser Ablation. Journal of Korean Physical Society. 2010;56(3):836-841.

15. Pathak D, Bedi RK, Kaur D, Kumar R. Fabrication of Densely Distributed Silver Indium Selenide Nanorods by Using $\mathrm{Ag}+$ Ion Irradiation. Journal of Korean Physical Society. 2010;57(3):474-479.

16. Singh KJ, Singh N, Kaundal RS, Singh K. Gamma-ray shielding and structural properties of $\mathrm{PbO}-\mathrm{SiO} 2$ glasses. Nuclear Instruments and Methods in Physics Research Section B: Beam Interactions with Materials and Atoms. 2008;266(6):944-948.
17. Nogami M. Glass preparation of the $\mathrm{ZrO} 2-\mathrm{SiO} 2$ system by the sol-gel process from metal alkoxides. Journal of Non-Crystalline Solids. 1985;69(2-3):415-423.

18. Singh N, Singh R, Singh KJ, Sing K. $\gamma$-ray shielding properties of lead and bismuth borosilicate glasses. Glass Technology. 2005;46(4):311-314.

19. Lee CM, Lee YH, Lee KJ. Cracking effect on gamma-ray shielding performance in concrete structure. Progress in Nuclear Energy. 2007;49(4):303-312.

20. Medhat ME. Gamma-ray attenuation coefficients of some building materials available in Egypt. Annals of Nuclear Energy. 2009;36(6):849-852. 